University of Nebraska - Lincoln

DigitalCommons@University of Nebraska - Lincoln

May 1990

\title{
Magnetic and structural properties of CoCrTa films and multilayers with $\mathrm{Cr}$
}

\author{
David J. Sellmyer \\ University of Nebraska-Lincoln, dsellmyer@unl.edu \\ D. Wang \\ University of Nebraska - Lincoln
}

J.A. Christner

Imprimis/CDC, Minneapolis, Minnesota 55435

Follow this and additional works at: https://digitalcommons.unl.edu/physicssellmyer

Part of the Physics Commons

Sellmyer, David J.; Wang, D.; and Christner, J.A., "Magnetic and structural properties of CoCrTa films and multilayers with Cr" (1990). David Sellmyer Publications. 127.

https://digitalcommons.unl.edu/physicssellmyer/127

This Article is brought to you for free and open access by the Research Papers in Physics and Astronomy at DigitalCommons@University of Nebraska - Lincoln. It has been accepted for inclusion in David Sellmyer Publications by an authorized administrator of DigitalCommons@University of Nebraska - Lincoln. 


\author{
D. J. Selimyer and D. Wang \\ Behlen Laboratory of Physics and Center for Materials Research and Analysis, University of Nebraska, \\ Lincoln, Nebraska $68588-0111$ \\ J. A. Christner \\ Imprimis/CDC, Minneapolis, Minnesota 55435

\begin{abstract}
We report our studies of epitaxial growth of CoCrTa films on $\mathrm{Cr}$ underiayers and the properties of $\mathrm{CoCrTa} / \mathrm{Cr}$ multilayers. The coercivity, $H_{c}$, strongly depends on $\mathrm{Ta}$ composition, sputtering conditions, and the thicknesses of the magnetic layer and $\mathrm{Cr}$ underlayer. An $H_{c}$ value of $1300 \mathrm{Oe}$ was obtained for a $\mathrm{Ta}$ composition of 2 at. \%, a $\mathrm{Cr}$ underlayer thickness of $4000 \AA$, and a magnetic layer thickness of $400 \AA$. The $\mathrm{x}$-ray data show that the high $H_{c}$ occurs when crystallites of the $\mathrm{Cr}$ uncerlayer and $\mathrm{CoCrTa}$ layer are aligned with the $\mathrm{Cr}(200)$ and CoCrTa (110) planes in the film plane. Thus, the $c$ axis of the CoCrTa lies essentially in the plane of the film. When the thickness of the magnetic layer increases above $1000 \AA$ the $c$ axis begins to tip out of the film plane. The basal plane lattice parameter varies roughly linearly with Ta content up to 13 at. \%. For the CoCrTa/Cr multilayered films, $H_{c}$ values up to 1200 Oe were obtained although the $c$-axis orientation of the magnetic layer becomes somewhat dispersed. Models for the dependence of magnetization reversal on microstructure are discussed.
\end{abstract}

\section{INTRODUCTION}

CoCr films have been widely studied for both perpendicular and longitudinal magnetic-recording media. ${ }^{1}$ As longitudinal recording media, the major disadvantage of $\mathrm{CoCr}$ is its relatively low coercivity. Many efforts have been made to improve it through a thick $\mathrm{Cr}$ underlayer or additive thitd element $(\mathrm{Ta}, \mathrm{W}, \mathrm{Nb}),^{2,3} \mathrm{With}$ a thick enough $\mathrm{Cr}$ underlayer $(>3000 \mathrm{~A})$ and the addition of a few atomic percent $\mathrm{Ta}$, high $H_{c}$, high signal-to-noise ratio, good frequency response, and good corrosion resistance have been obtained. ${ }^{3,4}$ Tamai et al. ${ }^{5}$ found that $c$ orientation is improved and grain size increases by $\mathrm{Ta}$ addition. Various magnetization reversal modeis have been proposed for CoCr films, and this depends on details of the anisotropy, texture, thickness, etc. ${ }^{6.7} \mathrm{We}$ report here some results on the effects of $\mathrm{Ta}$ addition, present data on the arigular dependence of $H_{c}$ for $\mathrm{CoCr}$ and $\mathrm{CoCrTa}$ films, give thickness dependence results on $\mathrm{CoCr}$ $\mathrm{Ta} / \mathrm{Cr}$ multilayers, and discuss the resulis in terms of existing models.

\section{SAMPLE PREPARATION AND MEASUREMENT}

Films were prepared in a multiple-gun de sputtering system. Both the CoCrTa layer and $\mathrm{Cr}$ underlayer were sputtered in the same pumpdown of the chamber. Samples were deposited on both copper and giass substrates which were mounted on a temperature-controlled electric furnace; the former were used for magnetization measurements and the latter for diffraction and fluorescence measurements. Substrate temperatures, $T_{s}$, were measured by a thermocouple clamped to the substrate. $T_{s}$ values between 20 and $500^{\circ} \mathrm{C}$ were investigated and it was found that $H_{c}$ was maximized for $370^{\circ} \mathrm{C}$. This is consistent with the annealing studies of $\mathrm{CoCr}$ films. ${ }^{8}$ Ta pieces were put on the top of a $\mathrm{CoCr}$ alloy target whose composition was 86 at. \% Co and 14 at. \% Cr. The base pressure was below $5 \times 10^{-7}$ Torr and the argon pressure during sputtering was $30 \mathrm{mT}$ Torr. The thickness of the $\mathrm{Cr}$ underlayer was kept at $4000 \AA$ while that of $\mathrm{CoCr} T a$ was $400 \AA$, except as otherwise mentioned. Individual layer thicknesses of $\mathrm{CoCrTa} / \mathrm{Cr}$ multilayered films were controlled by programming the time that the substrate was stationary above the corresponding target. Alloy compositions were measured using a Kevex $x$-ray fuorescence spectrometer. It is estimated that the uncertainties in the $\mathrm{Co}$ and $\mathrm{Cr}$ compositions are about $2 \%$ and in the $\mathrm{Ta}$ composition, $5 \%$. The structure was checked by $\mathrm{x}$-ray diffraction. Vibrating sample magnetometry was used to measure the magnetic properties at room temperature, with a maximum field of 18 kOe.

\section{RESULTS AND DISCUSSION}

\section{A. Structure}

Typical x-ray diffraction data are shown in Fig. 1 for films with different thicknesses. There is only a strong CoCrTa(110) peak for the film of $400 \AA$ besides the $\mathrm{Cr}(110)$ and (200) peaks. The basal plane CoCrTa(002) peak is very near the $\mathrm{Cr}(10)$ peak. High resolution $\mathrm{x}$-ray data show a single Gaussian distribution of $\mathrm{Cr}(110)$ and no $\mathrm{CoCrTa}(002)$. This means the film is oriented with $c$ axis parallel to the film plane which is preferred in longitudinal recording. For films thicker than $1000 \AA$ and multilayered films, a weak CoCrTa(101) peak began to appear, which means the $c$ axis started to tip out of the film plane, but there was still a strong $c$ orientation in plane. It is interesting to note that the basal plane lattice parameter, $a$, increases roughy linearly with $\mathrm{Ta}$ composition up to 13 at. \% (Fig. 2). Figure 2 also gives the calculated curve using a linear substitution formula and the covalent radius of Ta $(1.34 \AA)$. This may suggest that the Ta atoms go into CoCr substitutionally. The total change is about $0.5 \%$. 


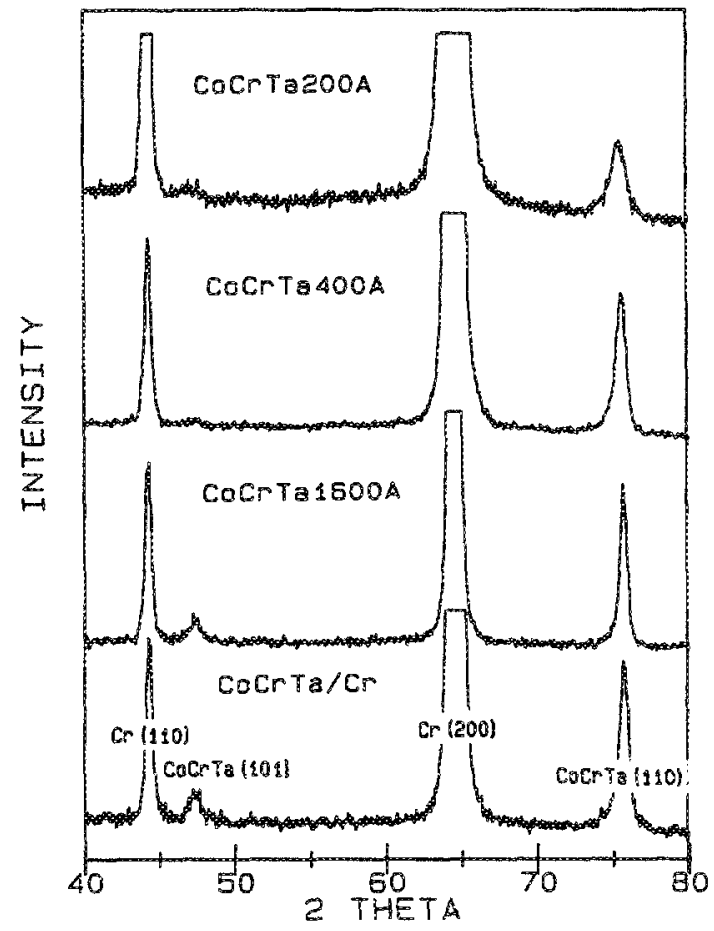

FGG. 1. X-ray diffraction patterns of CoCrTa films with thicknesses of 200 , 400 , and $1600 \AA$, and a CoCrTa/Cr multilayered film with magnetic layer thickness of $400 \AA$.

\section{Magnetic properties}

The parallel coercivity $H_{c}$ (in the plane of the film) is dependent on Ta concentration, film thickness, sputtering conditions, and the thickness of the $\mathrm{Cr}$ underlayer. ${ }^{3}$ Figure 2 shows the relationship between $H_{c}$ and the Ta concentration. There is a peak of $H_{c}$ around 2 at. \% Ta where $H_{c}$ is 200 Oe bigger than that of $\mathrm{CoCr}$ fim. High $\mathrm{Ta}$ concentration makes $H_{c}$ smaller and magnetization lower, so most of the samples were made with 2 at. \% $\mathrm{Ta}$. It is known that $\mathrm{CoCr}$ films exhibit particulate behavior. $H_{c}$ depends on crystalline anisotropy, the coupling strength among the particles, and the particle size and shape which affect the magnetization

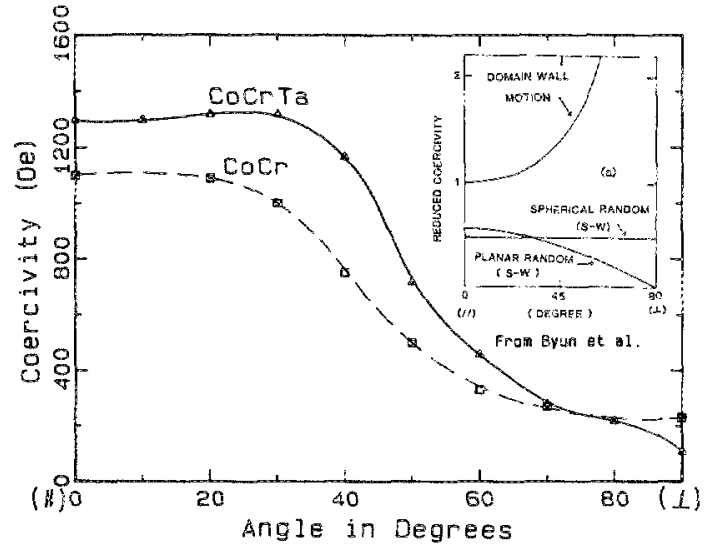

FIG. 3. $H_{c}$ as a function of the angle between the applied field and the film plane for $\mathrm{CoCr} \mathrm{Ta}$ and $\mathrm{CoCr}$ films. The inset shows calculated curves with planar random $\$$ W model and the domain-wall motion model from Ref. 7.

rotation. ${ }^{6}$ It is difficult to explain this complex Ta dependence of $H_{c}$ by the formula

$$
H_{c}=C\left(2 K / M_{s}\right)-N_{\text {cff }} M_{s},
$$

where $C$ is a constant, $K$ is the uniaxial anisotropy, $M_{s}$ is the magnetization, and $N_{\text {eff }}$ is an effective demagnetization factor. Several magnetization-reversal mechanisms for $\mathrm{CoCr}$ films have been suggested, including domain-wall motion, Stoner-Wohifarth ( $\mathrm{SW}$ ) coherent rotation, and incoherent rotation. ${ }^{6,7}$ We have measured the angular dependence of $H_{c}$ for a number of samples. Some data are shown in Fig. 3. In the case of a longitudinal magnetic recording fim having an in-plane easy axis, the inset portion of Fig. 3 gives the theoretical variations of $H_{c}$ as a function of the angle of the applied field with respect to the film plane, for domain-wall motion and planar random SW behavior. ${ }^{7}$ These calculations do not include a demagnetization field which is likely to be present in our films. Both $\mathrm{CoCr}$ and $\mathrm{CoCrT}$ a curves are qualitatively similar to the $\mathrm{SW}$ planar random result. For films with diferent thicknesses, the angular dependencies of $H_{c}$ are shown in Fig. 4. The two thimer films, one of $200 \AA$

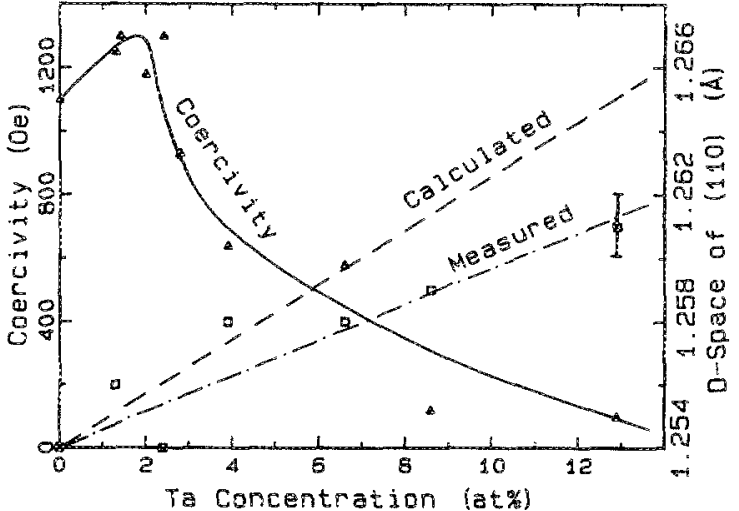

FIG. 2. Ta composicional cependence of $H_{\mathrm{c}}$ and lattice parameter, $a_{8}$ of the bassl plane $\mathrm{CoCr} \mathrm{T}$ (110). The error bar shown is representative of that for all the lattice parameter data.

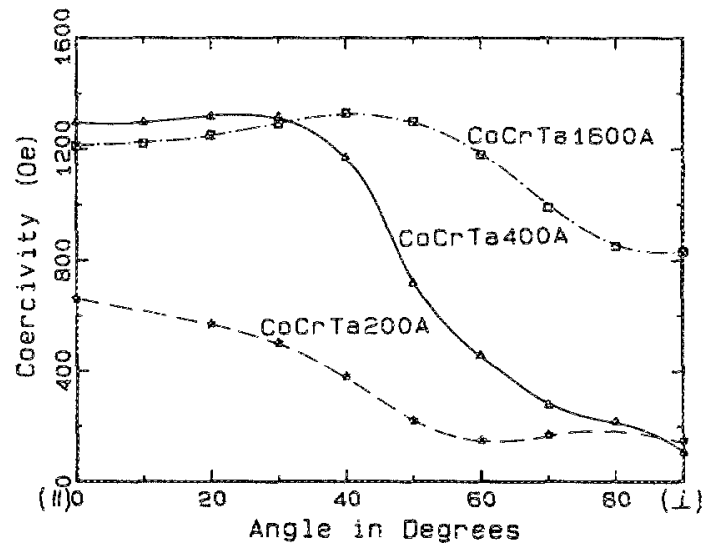

FIG. 4. $H_{c}$ as a function of the angle between the applied field and the film plane for CoCrTa films with different thicknesses of 200,400 , and $1600 \AA$. 


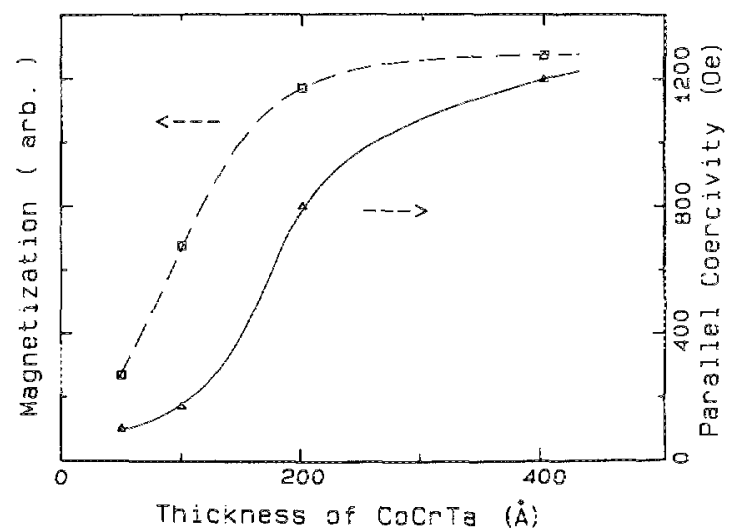

FIG. 5. CoCrTa layer thickness dependence of $H_{c}$ and magnetization for $\mathrm{CoCrTa} / \mathrm{Cr}$ multilayers.

thick and the other of $400 \AA$, behave similar as described by the planar random $S W$ model rather than domain-wall motion. The film of $1600 \AA$ thickness shows an obvious peak and $H_{c}$ in the perpendicular direction is quite large. One possibility for $H_{c}$ in the perpendicular direction being different from zero is that the $c$ orientations become dispersed for thick films, which is supported by the x-ray diffraction data. Figure 5 gives the data for $\mathrm{CoCrTa} / \mathrm{Cr}$ multilayered films with constant $\mathrm{Cr}$ thickness of $50 \AA$ and constant $\mathrm{Cr}$ underlayer thickness of $4000 \AA$. The total magnetic layer thickness is about $1200 \AA . H_{c}$ and the magnetization decrease very rapidly as the CoCrTa layer becomes less than about $200 \AA$. This behavior may be caused by both the smaller grain size and the strong interface atomic diffusion.

\section{SUMMARY}

In Ta-doped CoCr films, a maximum $H_{c}$ value of 1300 Oe was obtained under the conditions of 2 at. $\% \mathrm{Ta}, 400-\AA$ thick $\mathrm{CoCrTa}$, and $4000-\AA$-thick $\mathrm{Cr}$ underlayer at $370^{\circ} \mathrm{C}$. High $H_{c}$ occurs when the $\mathrm{Cr}(200)$ and $\mathrm{CoCrTa}(110)$ are aligned in the film plane. When the thickness of the magnetic layer increases above $1000 \AA$, the $c$ axis begins to tip out of the film plane and $H_{c}$ decreases slowly. For the thinner films the angular dependence of $H_{\mathrm{c}}$ is similar to that described by the SW planar random model, while for thicker films the data may be the result of the combined effects of planar random SW rotation and domain wall motion. High $H_{c}$ is obtained for a CoCrTa/Cr multilayered film when the magnetic layer is thick enough. It will be of interest to study the variation of coupling between $\mathrm{CoCr}$ Ta layer by changing the Cr-layer thickness.

\section{ACKNOWLEDGMENT}

We are grateful for financial support at the University of Nebraska to Contro! Data Corporation under Grant No. 87N106. We thank K. D. Aylesworth, Z. S. Shan, and J. X. Shen for assistance and helpful discussion.

'N. Tsumita, 3. Appl. Phys. 61, 3143 (1987).

${ }^{2}$ T. Lin, R. Alani, and D. N. Lambeth, J. Magn. Magn. Mater. 3, 78 (1989).

${ }^{3}$ J. C. Allan and R. D. Fisher, IEEE Trans. Magn. MAG-23, 122 (1987).

${ }^{4}$ J. A. Christner, R. Ranjan, R. L. Peterson, and J. I. Lee, J. Appl. Phys. 63, 3260 (1988)

${ }^{5}$ H. Tamai, IEEE Trans. Magn. MAG-24, 2347 (1988).

${ }^{6}$ A. Aharoni, IEEE Trans. Magn. MAG-22, 478 (1986).

${ }^{7} \mathrm{C}$. Byun, J. M. Sivertsen, and J. H. Judy, IEEE Trans. Magn. MAG-22, $1155(1986)$

${ }^{8} \mathrm{~S}$. Honda, N. Yamashita, M. Ohkoshi, and T. Kusuda, IEEE Trans. Magn. MAG-20, 791 (1984). 